\title{
The state of Canadian cities: theoretical and applied themes: an introduction
}

\author{
Laura A. Reese
}

Published online: 3 March 2009

(C) Springer Science+Business Media B.V. 2009

The initial goal of this Geojournal symposium was to provide readers with a holistic sense of the current state of research on and conditions in Canadian cities. While the composite articles certainly achieve this goal, the symposium also speaks to larger issues of urban history, current trends and future trajectories both for urban regions themselves but also for urban scholarship. Several aspects of the symposium are worth note. First, the call for papers for the symposium did not identify preferred specific foci for the research as far as topic or field. As will be become clear, however, the articles as a group highlight several critical themes that represent an urban research agenda for the 21st century, as well as the need for a corresponding urban policy agenda. The papers also reflect the inherent interdisciplinarity of urban research in both a normative and applied sense. The interdisciplinarity is also represented in the particular research methods employed, providing a rich and multifaceted look at the Canadian urban system. Finally, the symposium as a whole highlights the complexity of, yet critical need for, effective and thoughtful urban public policy-making in a rapidly globalizing world. One of the most pervasive themes

L. A. Reese ( $\square)$

Global Urban Studies and Political Science,

Michigan State University, 447 Berkey,

East Lansing, MI 48824, USA

e-mail: reesela@msu.edu

URL: www.gusp.msu.edu of the research presented here is the importance of past trends as well as the external forces of globalization in shaping current urban realities. Urban policy-making is inherently limited by path dependency and the natural advantages (or disadvantages) of cities as they take their places in the urban hierarchy. Increasing social and economic globalization adds a rapidly changing external environment over which individual cities or even urban regions, no matter how integrated, have little control. Yet, place and politics still matter; livable, sustainable and governable cities will be those that find room within these forces for effective local efforts to address and perhaps even shape change.

\section{Interdisciplinarity}

One of the most important contributions of this symposium is that it is interdisciplinary in approach. Political science, planning, public health, geography, and environmental studies are represented in the backgrounds of the authors. The fact that all are focused on trends within the Canadian urban system highlights the necessity of understanding urban areas holistically. There is no way to disconnect the economic from the political, from the social, from the environmental in urban processes. And, to try and do so ensures that findings and policy prescriptions will be limited and only marginally effective. Increased immigration can drive innovation and 
creativity, creating the economic and cultural diversity that attracts highly educated workers. At the same time it can increase competition between racial and ethnic groups, place pressure on housing markets and the environment, and provoke political contention. Building on formerly protected green spaces will likely lower housing prices and attract businesses looking for lower cost land, but it may also threaten long term environmental sustainability, make the area less attractive to prospective residents, and potentially endanger local health. These competing goals require that urban scholars and policy-makers focus on the forest rather than the trees.

In addition to providing a range of disciplinary perspectives, the volume also highlights a variety of methodologies for researching urban issues: statistical analysis of census data, case studies, face-to-face interviews, network analysis, geographic information system (GIS) analysis, and pollution regression mapping-combining statistical and spatial analysis. This reinforces the contention that different disciplines bring valuable methods to bear on the same issues. Narrow reliance on statistical analyses for example will miss both spatial patterns and attitudinal and political nuances ultimately responsible for the success or failure of policy initiatives-sprawl control or economic and spatial equity for example. Lack of long-term demographic analysis may lead to an assumption of deindustrialization where loss of manufacturing jobs may not actually be as extreme. Both of these cases are highlighted in symposium articles.

\section{Common themes}

Despite the interdisciplinary and varied research methods represented in the articles, there nevertheless are some common and important themes that say much about current and future trends in Canadian urban systems. Looking across the papers, the following stand out:

- Globalization and economic change

- New economy/knowledge economy

- Sustainability: environmental and economic

- Urban path dependency

- Equity: environmental, racial, economic, political, inter-city
- Importance of immigration

- Comparative contexts

These trends are tied, at least to some extent, to changes in the global economy or other processes of globalization. The increasingly global nature of economic production drives the shift from manufacturing to knowledge employment, challenges the sustainability of urban regions, stimulates immigration flows, divides cities and workers into haves and have nots depending on their readiness to embrace economic change, and intensifies the competition between cities and regions for workers, residents, and capital investment. While the shift from a manufacturing to a tertiary or service-based economy is fact, the rapidity of change and the extent that a knowledge-based economy will ensure current and future economic sustainability is still very much open to debate within academic and policy circles. The changing global economy raises a host of critical questions related to cities. How rapid and complete has been the shift from manufacturing to knowledgebased employment? Has the process taken place differentially between types of cities or across space? Are urban areas with more knowledge, technological or creative jobs, or skilled residents faring better economically? Will more new economy workers and employers assure future economic growth and sustainability? And, most importantly, are there effective policies to address the challenges raised by changing global circumstances? Whose interests are represented in shaping or selecting among those policies? To the extent that these trends are occurring in cities across North America, direct comparisons of Canadian and US responses become more important as they highlight both similarities and differences that may shed light on effective policy options.

Three of the articles deal directly with economic issues, more specifically the importance of the tertiary employment sector variously called the knowledge economy, high technology sector, new economy, or the more trendy "creative class." While casual and even academic use of these terms abound, there is a dearth of empirical work assessing the extent of trends, differentials among urban regions, effectiveness of policies to address the changes, and ultimately, the equity and political (in the most basic sense of who gets what and what voices are heard) impacts of proposed and implemented policies. 
The importance of the shift from manufacturing to knowledge based employment and production leads directly to concerns about sustainability. While discussion of "sustainable cities" has most often focused on environmental issues, the long-term viability of cities is dependent on economic, political, and social factors as well. "Sustainable development" as applied to city-regions focuses on the trade-offs between economic growth (often represented by land use patterns such as sprawl) and impact on the environment (Hawkin et al. 1999). Ultimately a sustainable metropolitan system is "one that shows a high degree of adaptability to global and technological change and in which the economy moves to higher levels of productivity rather than stagnating or collapsing into chaos" (Innes and Booher 1999, p. 150).

But, how much of the current and future sustainability of urban regions is due to path dependency or simple place luck? Much research has suggested that past economic and demographic trends strongly influence current and future economic prosperity. Historic spatial patterns of immigrant settlements can create voluntary enclaves that foster economic and political power or lead to dispersion that dilutes those outcomes. Past trends in economic production are extremely hard to change, as is evident in efforts of smaller cities to shift from traditional to new economy employment. In this symposium historic spatial settlement can cause environmental injustice in some cases (Seattle) but not in others (Vancouver). The historic location of relatively immobile infrastructure investments in airports, universities, and national or provincial capitals can confer extensive benefits on some cities while those lacking such amenities are hard pressed to reproduce them. A variety of factors make some cities and regions more desirable than others: good weather, proximity to natural features such as water and mountains, accessibility to other large urban centers, access to transportation networks, and location of cultural institutions and entertainment options. Is it possible that these accidents of history and location have a far greater impact on economic health than any deliberate policies of local government?

Issues of equity are central to urban systems whether the discussion is about differences among cities in economic fortunes or within cities between racial, ethnic, or income groups. While some Canadian urban areas are facing decline, others have had to deal with rapid rates of growth. Stressed urban areas deploy economic development initiatives to counter disinvestment and in some cases adapt land use and services to dwindling population and economic activity. Meanwhile, growing metropolitan regions must deal with the financial, environmental and quality of life implications of development in the present context, characterized by limited public sector budgets for new or upgraded infrastructure, crippling traffic congestion and concerns about different forms of pollution and climate change. In some cases growth of some cities is at the expense of others. How these changes affect the general urban system within Canada is inherently an equity issue as globalization creates urban winners and losers.

Within cities, political, economic and quality of life factors are not necessarily distributed equally across space and groups. How policy debates are framed reflects political power systems and also determines who benefits from the process. Land use policy framed in environmental terms can bring actors together in a battle where everyone can "win" by achieving a healthier, more attractive urban region. The same land use goals framed in redistributive or racially based terms can exacerbate divisions, leading to outcomes that promote the status quo. Depending on the local culture, economic development policies can reflect development-based interests or can promote broader community agendas. These issues are reflected in symposium articles.

Most contemporary discussions of globalization and cities turn at some point to the issue of immigration. To Richard Florida (2002), immigration and its attendant diversity (and presumed tolerance) is a driving force behind innovation, quality of life, and economic growth. For countries such as Canada with limited internal population growth, there is a more direct economic need for the skills immigrants bring with them. If immigration is truly a primary economic driver then where immigrants choose to locate is also an important feature of inter-city equity. The articles in the symposium highlight the importance of immigration to knowledge-based economies while at the same time providing a cautionary note about the limits of relying on immigration as an economic development panacea. In short, it may be a strategy that works for some cities but not others.

Finally, several of the papers raise the issue of the supposed "exceptionalism" of Canadian cities-an 
argument suggesting that the history and nature of Canadian urban areas is essentially unique and incomparable to other, particularly US, urban areas. The articles in the symposium suggest that exceptionalism is simply not the case. While the trajectories may be different, North American cities are facing the same global challenges with similar effects on economic systems. Economic growth, sprawl, deindustrialization and environmental quality are common trends across cities in North America and beyond. Governing regimes and urban power systems are important frames for understanding how policies are made. There is strong evidence that there are important differences between cities and policy responses in Canadian and US urban areas (the focus of articles in this volume), however. The racial histories and ethnic divisions are very different in the two countries with implications for urban policymaking. Cleavages between race, ethnicity, and spatial settlement patterns vary with potential impacts on environmental justice. Some recent studies suggest that regime types rare in the US-inclusive or progressive regimes - are more common in Canada. The articles in the volume provide an interesting view of similarities and differences among cities in Canada and the US, raising interesting future research questions. Clearly, comparative (as well as interdisciplinary) research is central to fully understanding urban systems.

\section{Article summaries}

The article by Filion sets the stage for the symposium by presenting a nation-wide assessment of past and current economic trends in Canada and their impacts on the urban system, setting up many of the themes that follow. While the historic economic cleavage in the country has been between the industrial heartland and the resource-based hinterland, Filion persuasively argues that the current and future divide will increasingly lie between a few large "have" cities and many smaller "have-not" cities. In addition to differences in economic base (with 21st century knowledge and service economy jobs agglomerating in the former), immigration patterns dictate segregation as well. This reality will create a polarized urban landscape divided by economic growth, race, culture and, increasingly, political power. Filion describes a scenario where larger or, in the language of other articles in this volume, knowledge cities are advantaged by past agglomerations of highly educated and skilled workers, high technology industries, and immigrant fueled population and economic growth. They will continue to prosper while smaller cities, not so historically advantaged, increasingly decline. This path dependent process reoccurs in almost every article in the volume. And, in this macro analysis, cities with "place luck" solidify their positions as they become more influential on the national scene as economic power begets political power. Inequalities in power are expected to be exacerbated by national and provincial politics generally unfavorable to economic intervention and hesitant about regional solutions that might only serve to strengthen urban power vis-à-vis the provinces. Thus, the large city/ small city disparity will be almost impossible to overcome for the latter unless they have some of the critical economic success features identified in the Sands article that follows: proximity to one of the large cities, a high quality university, or natural features that promote tourism such as the environment of the Pacific Southwest.

The process described by Filion where population and knowledge employment increasingly cluster in urban centers at the expense of smaller cities and non-urban areas creates impacts on a host of other urban issues outlined in this symposium: the environment, green space, and regional sustainability ( $\mathrm{Su}$ et al., Wekerle and Abbruzzese); political representation within and between cities (Filion, Klein and Tremblay); and the future economic viability of the entire urban system and concomitant public policies to ensure it (Sands, Novakowski). It appears likely that Canadian urban conflicts will continue to focus on large city/small city polarization with serious implications for public policy at all levels of government. For larger cities this portends increasing power on the provincial and national scene, need for social and built environment infrastructure (potentially placing pressure on current green spaces), and conflicts between powerful city regions and provinces. At the same time the smaller have-not cities will call for economic aid and greater policy intervention in the economy. To the extent that larger cities attract the bulk of the country's immigration, this also sets up a potential cultural conflict between areas with diverse racial and ethnic groups and those 
more homogeneously composed of "native" Canadians.

The Sands article focusing on specific city regions-Toronto, Vancouver, and Montréal-fits nicely within the framework posed by Filion, as it compares more recent economic trends in the three largest Canadian central cities with their satellite urban areas. Specifically the examination concentrates on changes in traditional manufacturing and new economy employment, a topic currently central to discussions about how to redevelop local economies. If human resource development theories are correct, cities that can attract or develop more new economy jobs will experience greater economic stability and growth over the long run.

In a comparative sense, the Sands' analysis suggests that Canadian cities have not yet experienced the levels of deindustrialization prevalent in cities in the United States. Yet, the three large city centers have done better than their constituent suburbs in retention of traditional manufacturing jobs and development of new economy jobs. Indeed, manufacturing employment has decreased over the past decade in most suburban communities that seem to have less ability to replace those jobs with higher order service, technology, or artistic employment. The only outlying cities to defy this trend are those that are within easy commuting distance to their respective large city, have prominent universities or colleges, or, in the case of Victoria, are tourism centers in their own right. And, as human resource theories suggest, communities with more new economy employment appear to have better economic health over time.

Yet, Sands provides a sobering cautionary tale with specific application to local economic development policy. Urban economic health, as represented by the prosperity of residents, is highly path dependent. Cities that were healthier in the past remain healthier in later years. New economy jobs are correlated with future economic health-if a city had more of those in the past it will also have more in the future. Thus, if an unlucky city has a historic pattern of traditional manufacturing, current manufacturing job loss, and a slower rate of new economy growth, what can it possibly do to change its fortunes? Once a city develops its place in the urban hierarchy is there any way to alter that position? On the one hand the policy implications suggested by
Sands are not promising; the natural amenities that attract tourists or the major university that stimulates new economy jobs are not mobile, and in the latter case are extremely hard for cities to develop. New economy jobs, then, may not be a panacea for smaller cities. Immigration and diversity also do not appear to correlate with economic health, at least for this set of smaller Canadian cities, suggesting that some urban areas cannot hope for the magnitude of immigration that stimulates innovation and job growth. Sands' analysis strongly suggests that for larger urban centers the path to growth may well be through immigration and the new economy-well in line with the prognostications presented by Filion-while for the many smaller cities and suburban communities, development strategies might be better focused on quality of life and sustainability for existing residents.

Novakowski's analysis of the "knowledge city" potentials of Ottawa provides a further case in point to the broader analyses presented by Filion and Sands. The article begins with a detailed description of the knowledge city capacities of Ottawa, where a set of positive attributes align: natural environments; capital city status; high education and skill levels for residents; a preponderance of knowledge and governmental jobs; strong innovation capacity; and widespread digital use. Novakowski points to many causes of concern, however, that threaten the future development of Ottawa as a leading knowledge center. These threats revolve around several issues: general decline in Ontario's economic health, decreasing Canadian enrollment in engineering programs, relatively low levels of immigration to Ottawa, lack of venture capital, poor transportation connectivity internally and externally in Ottawa, and local government tax structure. It appears that being a knowledge city may be a necessary but not sufficient condition to take advantage of economic opportunities. Appropriate public policies are also necessary to ensure that these advantages are capitalized on. In looking across the threats a general theme emerges, however; most are almost completely outside the control of local policy-makers in Ottawa and to some extent are outside of provincial control. Global economic forces contribute to provincial health, educational trends are national in scope, immigration is highly path dependent in that new immigrants tend to collocate with family, group, or community members preceding them, and the province is largely 
in control of the local tax structure. What are local officials, even in primary central cities, supposed to do to remove barriers to development and ensure future prosperity? This seems to be a recurring and difficult question.

The other articles in the volume raise concerns about some of the policies recommended for knowledge city development in Ottawa. First, expansion into the Ottawa Greenbelt appears to violate the environmental sustainability concerns raised in the Werkerlee/Abzzuassee and Su et al. analyses. What should the appropriate policy solutions be when economic and environment values and goals appear to conflict? If immigration is path dependent and must achieve a particular level of agglomeration before economic advantages are realized, is this an appropriate development strategy for cities such as Ottawa that have not been traditional immigrant attractors? Taken as a whole the analyses presented by the first three papers raise important questions about the future trajectories of Canadian cities within the global economy as well as policy challenges for local and provincial officials charged with stimulating economic growth.

The next three articles in the volume shift the focus somewhat from economic trends to governance, equity, and sustainability in Canadian cities. Research by Klein and Tremblay addresses governance trends in the City of Montréal. It provides an interesting case for regime analysis since regional government and power is highly fragmented yet the city operates within the context of the Québec governing model, which tends to be inclusive, participatory, and consensual. The questions then for economic development policy in Montréal are whether, given the fragmented nature of the region, there is a governing regime at all, whether the prevalent (at least in the US) development regime is present, or whether a different decision-making system operates because of the Québec governing culture.

Through case study and network analysis the authors find that there does appear to be a nascent regime in the city of Montréal that is open to a variety of actors including government, business, union, and cultural groups. Indeed, the case studies seem to indicate that development projects made within this inclusive context come to fruition while those that oppose it-by keeping decision-making within a more traditional development regime format—do not. The central role of cultural institutions within the governing framework provides an interesting extension of both creative class and regime analysis, to whit: if cultural institutions become more prevalent and powerful as the result of creative class development strategies, does this open the door for their greater and perhaps stable participation in urban governing regimes? Further, research has also suggested other inclusive regimes among Canadian cities not in Québec-in Vancouver and Ottawa for example-implying that development regimes may not be as common across Canada as they are in the United States.

Wekerle and Abbruzzese address a different kind of governing issue, more specifically related to regionalism and the extent to which regional coalitions can develop and lead to coherent regional policies, in this case those that address limits on sprawl or green space preservation. The Toronto and Rochester cases presented in this article provide interesting counterpoints on these issues. In the Oak Ridges Moraine case, the organizing focus for regional efforts is clearly packaged in the context of environmental preservation. In the Rochester antisprawl efforts the main focus is racial and economic equity. The simple conclusion is that environmental, as opposed to equity or redistribution, policies make a more politically palatable case for regional cooperation. The authors make clear that there are broader lessons to be learned from these cases, however. First, the elephant in the room is clearly the issue of race, particularly when racial cleavages coincide with economic ones. Regionalism in Rochester requires residents and participating governments to give up some of their sovereignty, place limits on their choice of residence (or more finely, on the choice of residence of others), and impose some responsibility for urban ills on suburban governments. The environmental issue in Toronto required only that local units work cooperatively to set aside current green space for future protection. While this may well hurt speculators and potential developers, the costs are not nearly as clear or divisive as in the Rochester case.

Further the locus of the regional efforts and participating actors are different. The Toronto effort had active grass roots participation of suburban units pulled together by a strong provincial role. In the Rochester case the mayor spearheaded the policy 
over suburban objections within a vacuum of state level participation. The coalition of faith-based groups was not sufficient to overcome suburban hostility to the proposal. What this article suggests about the future of regional solutions bodes well for future environmental protection and sustainability in Canadian cities, particularly those with provincial support. Larger regional solutions that might threaten prevailing power balances, that make large urban centers too powerful in provincial eyes (as suggested by Filion), and those that require redistribution, may well be less successful.

The article by $\mathrm{Su}$ et al. provides a different lens through which to explore issues of equity by providing a spatial assessment of air quality in the Vancouver and Seattle metropolitan areas. As an epistemological contribution the research shows the validity of the pollution regression mapping technique for measuring urban air quality and equity issues. On a more policy or political level, the research finds interesting differences between Canadian and US metropolitan regions in terms of environmental equity.

While it is not surprising to find, given previous research cited in the paper, that lower income households are more likely to be located in proximity to areas with poorer air quality, it appears that equity is more problematic in Seattle and that particular elements of the equity equation are not significantly correlated with air pollution in either city. For example, there is no correlation between the location of manufacturing sites and air quality. The authors suggest that this is the case because of manufacturing deconcentration in both cities. Thus, deindustrialization may have benefits for central cities but costs for the exurban sites receiving plants. Given that the Sands analysis showed little manufacturing job loss in Vancouver, it is possible that residents are maintaining their jobs but are having to commute longer distances to reach them; a situation that might be reflected in higher levels of pollution overall. Additionally, single-parent families do not appear to systematically reside closer to areas with poor air quality. Low median family income was the only economic stress indicator significantly correlated with environmental injustice in both cities.

Seattle evidenced a significant positive correlation between immigrant population and poorer air quality, a relationship not present in Vancouver. The authors raise several possibilities to explain this situation including the lack of freeways in Vancouver and historic patterns of immigrant settlement, again highlighting the importance of path dependency. While the possibility of deliberate policy actions is beyond the scope of the article, given the apparent importance of immigration and urban economic health noted in several of the articles, an assessment of Vancouver policies regarding immigrant settlement and air quality might provide an interesting connection between issues of economics, global settlement patterns, equity, political representation, and public policy.

\section{Implications for Canadian urban policy and future research}

The articles in this symposium suggest a number of interesting questions for future research. These relate to the central themes covered across the symposium and are highlighted below:

- To what extent will the polarization among large and small cities erect barriers to addressing the economic development challenges of the latter? Will smaller cities be able to gain the political clout necessary to pursue more active economic development agendas?

- As further declines in North America's automobile industry work through the Canadian economy, will the pace of deindustrialization increase? As this occurs will the importance of new economy jobs and immigration increase?

- If central economic challenges relate to immigration flows, business location decisions, university engineering enrollments, and stronger provincial and national economic health, to what extent can urban policy be expected to address these issues? In an increasingly global economy, what is the place of urban politics and policy or urban decision-makers?

- What will happen as economic growth in large cities places increasing pressure on greenbelts? Will growth trump environmental concerns?

- To what extent is the Québec model of governance limited to Québec? Are inclusive regimes more prevalent in Canada than in the US? Is the current inclusive regime in Montréal a stable, 
enduring one? Within civil society, what is the balance of power between business and community-based interests? Does the apparent inclusive regime for economic development policy extend to other policy areas in Montréal?

- Are policies that deal explicitly with redistribution or racial or ethnic group equity more likely in Canadian cities? How much does the different history of race relations in Canada and the US matter in intra-city equity issues whether they be economic, environment, or political?

- Does regionalism only work if the changes sought do not threaten extant government sovereignty or power arrangements or seek to limit or change citizen choices? In short, is the success of regional policy in Toronto relative to Rochester more about race than the environment?
These are inherently interesting questions about Canadian, and indeed, global urban systems. Perhaps the greatest value of the articles here are the extent to which they stimulate thought, highlight critical current issues in urban affairs, and point to fruitful areas of future study.

\section{References}

Florida, R. (2002). The rise of the creative class. New York: Basic Books.

Hawkin, P., Lovins, A., \& Lovins, L. (1999). Natural capitalism: The next industrial revolution. London: Earthscan.

Innes, J. E., \& Booher, D. E. (1999). Metropolitan development as a complex system: A new approach to sustainability. Economic Development Quarterly, 13, 141-156. 